\title{
Influence of Kosher (Shechita) and conventional slaughter techniques on shear force, drip and cooking loss of beef
}

\author{
B. Agbeniga, E.C. Webb ${ }^{\#}$ \& H.A. O’Neill \\ Department of Animal and Wildlife Sciences, University of Pretoria, 0002 Pretoria, South Africa
}

(Received 24 September 2012; Accepted 27 April 2013; First published online 19 August 2013)

Copyright resides with the authors in terms of the Creative Commons Attribution 2.5 South African Licence.
See: http://creativecommons.org/licenses/by/2.5/za/
Condition of use: The user may copy, distribute, transmit and adapt the work, but must recognise the authors and the South African Journal
of Animal Science

\begin{abstract}
The objective of this study was to evaluate the effects of Kosher (Shechita) and conventional slaughter methods on shear force, drip and cooking losses of beef ( $m$. longissimus dorsi samples) from South African feedlot cattle. Results revealed significantly lower shear force values for meat samples from cattle slaughtered by the Kosher method compared to those from cattle slaughtered by the conventional slaughter method. Cooking loss was significantly higher for meat samples from cattle slaughtered in the conventional way compared to those from cattle slaughtered by Kosher method. However, no significant difference was observed for drip loss between slaughter methods. These findings suggest that captive bolt stunning before sticking resulted in higher cooking losses and yielded less tender meat compared to the Kosher slaughter method.
\end{abstract}

Keywords: Sticking, stunning, tenderness, water holding capacity, yield

" Corresponding author: Edward.webb@up.co.za

\section{Introduction}

The effects of slaughter method on meat quality are controversial (Levinger, 1995; Gregory, 1998). Kosher slaughter has been criticized from meat and welfare perspectives and efforts have been made to render this method illegal or abolish it in countries like Britain, Spain, France, Germany and Denmark. Countries like Switzerland, Norway, Sweden and most recently, The Netherlands, do not allow religious slaughter on conscious animals (Levinger, 1995), while pressure is also mounting to regulate Kosher slaughter more strictly in South Africa. The advocates of Kosher slaughter claim that some carcass and meat attributes are better than when animals are stunned before sticking (conventional slaughter) (Miller, 1952; Levinger, 1995). Presently in South Africa, the slaughter regulation allows animals (cattle) to be slaughtered by means of the Kosher method provided they are stunned 20 seconds post-cut (Animal Protection Amendment Act, No 7 of 1991).

The aim of this study was to evaluate and compare the influence of conventional and Kosher slaughter methods on beef tenderness and water holding capacity in terms of drip and cooking losses. The work was necessitated by the growing consumer awareness in South Africa over the past decade regarding meat quality and animal welfare. There is also growing pressure on meat producers to comply with consumer preferences in terms of good quality meat with the best consistent eating qualities (Strydom, 1998). Poor animal welfare practices pre-slaughter or at slaughter can lead to inferior meat quality which results in loss of yield and loss of sales through rejection and downgrading of poor quality product (Gregory, 1998).

Meat tenderness remains one of the most important physical attributes of meat when eaten, after some degree of cooking (Swatland, 1984). O’Neill et al. (2005) found that pre-slaughter stress in South African feedlot cattle results in a higher ultimate $\mathrm{pH}$, cooking losses and tougher meat. There is also a perception that Kosher slaughter of cattle is more stressful and may result in less tender meat. The water holding capacity of meat (WHC) is an important quality attribute that influences the final yield of the cooked product and 
product value. Any loss of water reduces the weight of the product, which results in a financial loss (Rosenvolt \& Andersen, 2003). Water holding capacity is also important in terms of eating quality (Bertram et al., 2003; Cheng \& Sun, 2008). It is also known that WHC is affected by pre-slaughter treatments such as fasting and different stunning methods. Stunning may affect WHC through stress which reduces muscular glycogen reserves; this could lead to a high ultimate $\mathrm{pH}$ and low water content of meat (PSE meat) (Cheng \& Sun, 2008). The objective of this study was therefore to evaluate the effects of the Kosher (Shechita) and conventional slaughter methods on shear force and drip losses of beef ( $m$. longissimus dorsi samples) from South African feedlot cattle.

\section{Materials and Methods}

The animals used in this study were crossbred steers, representative of typical feedlot cattle in South Africa, in the "A" age group (cattle with no permanent incisors) according the current South African Beef Classification System (Meat Classification System Regulation No 863 in Government Gazette of September 2006). Average live weight of the cattle was about $400 \mathrm{~kg}$, pre-slaughter conditions were similar and animals were not unnecessarily stressed before slaughter. Transportation time from farm to abattoir was about three hours and all animals had about 12 hours of overnight lairage time with access to water, but without feed. Kosher slaughter was done by using a 0.22 calibre special captive bolt gun to stun the animals 20 seconds post-cut in an American Society for Prevention of Cruelty against Animals (ASPCA) pen (in which animals are slaughtered in an upright position), according to the current South African slaughter regulation (Animal Protection Act, No 7 of 1991). Conventional slaughter was done by stunning the animals with a pneumatic captive bolt gun for approximately 45 seconds before the cut.

Samples of the $m$. longissimus dorsi were cut from the $10^{\text {th }}$ to $11^{\text {th }}$ vertebrae, at about 24 hours post mortem, after the 24-hour $\mathrm{pH}$ and temperature readings were recorded on the carcasses. Samples were cut from the left side of each carcass. Samples were cut by means of a sharp knife and a saw by removing the $10^{\text {th }}$ to $11^{\text {th }}$ lumbar vertebrae. A total of 57 samples were collected from Kosher-slaughtered carcasses and 66 samples from conventionally slaughtered carcasses.

For drip loss determination, samples of approximately $30 \mathrm{~g}$ were cut from the $\mathrm{m}$. longissimus dorsi (L10-L11) with a knife and each was suspended with a thin wire from the lid of a sealed, transparent plastic bottle. This was done by drilling two holes through the lid and passing the wire through the meat and through the holes to suspend the meat without touching the container. This procedure allowed the meat samples to release the drip directly to the bottom of each container. Drip losses were determined after suspension for a period of 24 hours at a temperature of $4{ }^{\circ} \mathrm{C}$. After 24 hours, the samples were removed from the containers, gently blotted dry and weighed (Honikel, 1998; Knight, 1998). Drip loss was expressed as a percentage of the initial weight:

$$
\% \text { Drip loss }=\frac{\text { Weight loss after drip }}{\text { Initial sample weight }} \frac{100}{1}
$$

For the determination of cooking loss, meat samples of about $200 \mathrm{~g}$ to $400 \mathrm{~g}$ were cut from the same longissimus dorsi muscle samples that were cut and evaluated for cooking loss 36 hours post mortem. Samples were cut into rectangular shapes of about $8 \mathrm{~cm} \times 6 \mathrm{~cm} \times 5 \mathrm{~cm}$. Each sample was then placed in a thin-walled transparent plastic bag and placed in a bath with continuously boiling water, with the open end of the bag-extending above the water surface on a metal rack. This was done to prevent water from entering the plastic bags. The temperature of the water fluctuated between $75{ }^{\circ} \mathrm{C}$ and $80{ }^{\circ} \mathrm{C}$ and the samples were boiled for one hour. After boiling, the plastic bags were removed from the water bath and cooled in a bath of icecold water. Samples were then chilled and stored at $4{ }^{\circ} \mathrm{C}$ for 12 hours. After 12 hours of storage, the meat samples were removed from the bags, blotted dry and weighed (Honikel, 1998). Cooking loss was expressed as a percentage of the initial weight:

$$
\% \text { Cooking loss }=\frac{\text { Weight loss after cooking }}{\text { Initial sample weight }} \frac{100}{1}
$$

For shear force determination, the cooked samples that were used to determine cooking loss were also used to analyse the shear force of meat. After the determination of the cooking losses, the samples were 
blotted dry, cooled and shear force determined about 10 hours later. A hollow metal probe of $1.27 \mathrm{~cm}$ in diameter and $8 \mathrm{~cm}$ in length was used to take 10 samples from each block of meat along the length of the fibre arrangement (Kastner \& Henrickson, 1969; Destefanus et al., 2007). An Instron shear force apparatus was attached to an Instron machine, model 1101. Ten shear force values were measured on each core sample obtained from each block of meat. The shear was made perpendicular to the fibre arrangement (Honikel, 1998). The settings of the Instron apparatus for compression tests were as follows: Load transducer $=500 \mathrm{~N}$; gage speed $=38 \mathrm{~mm}$; testing speed $=500 \mathrm{~mm} / \mathrm{min}$; load range $=40 \%$; specimen type $=$ round; specimen dimension $=1.27 \mathrm{~cm}$. The average shear force of 10 cuts from each meat sample was calculated to obtain a shear force value and standard deviation for each sample.

Statistical analysis was done with transformed data because it was not distributed normally. The Proc GLM procedure of SAS (Version 9.2) was used to analyse the transformed data. Least square means (LS means) and standard deviations (SD) for each mean value were calculated and analysed. The Fisher's protected t-test and least significant difference (LSD) at a 5\% level of probability was used to test differences between LS means. Data in tables are presented as non-transformed values.

\section{Results}

Slaughter method did not influence drip loss of meat samples (Table 1). Meat samples from the conventional slaughter group exhibited higher cooking losses $(P<0.01)$ in comparison with those from the Kosher-slaughter group. Shear force differed significantly $(P<0.001)$ between meat samples from the two slaughter methods. Samples from the conventionally slaughtered carcasses were significantly less tender compared to those from the Kosher-slaughtered cattle.

Table 1 Effect of slaughter method on drip loss, cooking loss and shear force values of meat from typical South African feedlot cattle

\begin{tabular}{lccc}
\hline Slaughter Method & \%Drip Loss & \% Cooking loss & Shear Force (N) \\
Mean \pm SD & Mean \pm SD & SD \\
\hline Kosher & $2.14 \pm 1.15$ & $18.2^{\mathrm{a}} \pm 4.81$ & $43.0^{\mathrm{a}} \pm 15.8$ \\
Conventional & $2.7 \pm 1.34$ & $22.1^{\mathrm{b}} \pm 3.56$ & $53.5^{\mathrm{b}} \pm 12.3$ \\
\hline
\end{tabular}

${ }^{\mathrm{ab}}$ Means in the same column with different superscript letters differ $(P<0.05)$.

\section{Discussion}

In terms of drip loss, it is well known that stress (which decreases muscle glycogen reserves) and different stunning methods can influence drip loss of meat, although the reason for this is complex and not clearly understood (Cheng \& Sun, 2008). Results from the present study agree with those of Bertram et al. (2002) on pig longissimus dorsi muscle, in which captive bolt-stunned pigs exuded more water (drip) than electrically- and $\mathrm{CO}_{2}$ stunned pigs. Onec \& Kaya (2004) also reported that more water exuded from meat of captive bolt stunned cattle at seven days post mortem compared to non-stunned cattle. Vergara \& Gallego (2000), however, found no significant difference in drip loss between electrically stunned and non-stunned lambs. Dreyer et al. (1972) compared fibre in pigs slaughtered with or without captive bolt (non-stunned); in their study, captive bolt stun coupled with low $\mathrm{pH}$ caused a decrease in fibre diameter which led to loss of extracellular water and fibre shrinkage. It is known that $\mathrm{pH}$ is a key factor when it comes to drip loss (Bendall \& Swatland, 1988; Offer \& Knight, 1988; Kinsman et al., 1994; Cheng \& Sun, 2008). The pH profile data from the present study show that the post mortem drop in carcass-pH in carcasses from both slaughter groups were virtually similar and this could be a reason why there was no significant difference in drip loss. Initial carcass temperatures were also similar, but after three hours post mortem the differences became greater as the conventionally slaughtered carcasses cooled down faster.

Meat samples from the conventional slaughter group exuded more water when cooked (cooking losses).These results agree with the findings of Onec \& Kaya (2004) in which meat from captive-bolt- 
stunned cattle had significantly higher cooking losses at 7 and 14 days post mortem compared to the nonstunned group. Similar to drip loss, the rates of temperature and $\mathrm{pH}$ decline were faster in the conventionally slaughtered group which appears to be related to cooking losses. The 24 hour temperature for the conventional group was sub-zero $\left(-0.42{ }^{\circ} \mathrm{C}\right)$ while for Kosher, it was $3.06{ }^{\circ} \mathrm{C}$. The properties of water in muscle tissues are known to be temperature dependent and it could affect the chemical/physical state and distribution of water in muscle (Bertram et al., 2003; Savel et al., 2005). The stress that is experienced at stunning could also have played a role in this regard as it could cause physiological changes which include re-distribution of visceral blood volume towards skeletal muscle and brain among others. In this way, water is re-directed, causing more cooking loss (Ferguson \& Warner, 2008).

Differences in shear force between meat samples from the two slaughter methods can be attributed to a number of reasons. The first is the water content of the meat. The amount of water that is bound within meat fibres may affect tenderness (Currie \& Wolfe, 1980; Lawrie, 1998; Scheepers, 1999; Bertram et al., 2000). Results of the present study showed higher cooking losses for meat samples from conventionally slaughtered cattle. These higher cooking losses may have contributed to the higher shear force values of meat samples from the conventional slaughter group. Secondly, the 24 hour temperature and rate of temperature decline, which was faster in the conventionally slaughtered cattle, could have caused cold shortening and have played a role in sarcomere shortening; the latter could lead to higher shear force values in the conventionally slaughtered cattle (Locker \& Daines, 1975; Swatland, 1984; Scheepers, 1999). The effect of stunning per se could have resulted in a higher drip loss and as a result, tougher meat, as demonstrated by Bertram et al. (2000).

\section{Conclusion and recommendations}

From the present results, it is concluded that captive bolt stunning before sticking (conventional slaughter) results in higher cooking loss and shear force values for longissimus muscle samples compared to samples from Kosher-slaughtered cattle. More studies are recommended on WHC using Nuclear Magnetic Resonance (NMR) imaging to better understand the effect of stunning and stress on WHC, membrane integrity and the amount of myofibrillar water in meat. This may also help us to understand the relaxation and contraction patterns of meat.

\section{Acknowledgement}

This work was funded by the Red Meat Research and Development of South Africa (RMRD-SA).

\section{References}

Bendall, J.R. \& Swatland, H.J., 1988. A review of the relationships of pH with physical aspects of pork quality. Meat Sci. 24, 85-126.

Bertram, H.C., 2004. Field gradient CPMG applied on post-mortem muscles. Magnetic Resonance Imaging 22, 557-563.

Bertram, H.C., Andersen, H.J., Karlson, A.H., Horn, P., Hedegaard, J., Norgaard, L. \& Endelen, S.B., 2003. Prediction of technological quality (cooking loss and napole yield) of pork based fresh meat characteristics. Meat Sci. 65, 707-712.

Bertram, H.C., Perterson, J.S. \& Andersen, H.J., 2000. Relationship between RN genotype and drip loss in meat from Danish pigs. Meat Sci. 56, 49-55.

Bertram, H.C., Stodkilde-Jorgensen, H., Karlson, A.H. \& Andersen, H.J., 2002. Post-mortem energy metabolism and meat quality of porcine $m$. longissimus dorsi as influenced by stunning method- A ${ }^{31}$ PNMR spectroscopy study. Meat Sci. 62, 117-119.

Cheng, Q.F. \& Sun, D.W., 2008. Factors affecting the water holding capacity of red meat products: A review of recent research advances. Crit. Rev. Food Sci. Nutr. 48, 137-159.

Currie, R.W. \& Wolfe, F.H., 1980. Rigor related changes in mechanical properties (tensile and adhesive) and extracellular space in beef muscle. Meat Sci. 4, 122-143.

Destefanus, G., Brugiapaglia, A., Barge, M.T. \& Dal Molin, E., 2008. Relationship between beef consumer tenderness perception and Warner-Bratzler shear force. Meat Sci. 78, 153-156.

Dreyer et al., 1972. In: Swatland, H.J., 1984. Structure and Development of Meat Animals (p. 386). Prentice Hall, Inc., Egelwood Cliffs, New Jersey 07632. 
Ferguson, D.M. \& Warner, R.D., 2008. Have we under-estimated the impact of pre-slaughter stress on meat quality in ruminants. Meat Sci. 80, 12-19.

Gregory, N.G., 1998. Animal welfare and Meat Science. Cambridge, UK: University Press.

Honikel, K.O., 1998. Reference methods for the assessment of physical characteristics of meat. Meat Sci. 49, 447-457.

Kastner, C.L. \& Henrickson, R.L., 1969. Providing uniform meat cores for mechanical shear force measurement. J. Food Sci. 34, 603-605.

Kinsman, D.M., Kotula, A.W. \& Bredenstein, B.C., 1994. Muscle Foods. Chapman and Hall, New York, NY 10119.

Lawrie, R.A., 1998. Meat Science (6 ${ }^{\text {th }}$ ed). Cambridge: Woodhead Publishing Ltd.

Levinger, I.M., 1995. Shechita in the light of the year 2000. Critical view of the scientific aspects of methods of slaughter and Shechita. Mahon, L’David: Jerusalem.

Locker, R.H. \& Daines, G.J., 1975. Rigor mortis in beef sternomandibularis muscle at $37{ }^{\circ} \mathrm{C}$. J. Sci. Food Agric. 26, 1721-1733.

Miller, A.R., 1952. Meat Hygiene. Lea and Febiger, Philadelphia.

Offer, G. \& Knight, P., 1988. The structural basis of water holding in meat; Part 2: Drip losses. In: Developments in Meat Science. ( ${ }^{\text {th }}$ ed.). Ed: Lawrie, R.A., Elsevier, Oxford. pp. 173-241.

Onec, A. \& Kaya, P., 2004. The effects of electrical stunning and percussive captive bolt stunning on meat quality of cattle processed by Turkish slaughter procedures. Meat Sci. 66, 809-815.

O’Neill, H.A., Webb, E.C., Frylinck, L. \& Strydom, P.E., 2004. The stress responsiveness of three different beef breed types and the effects on ultimate $\mathrm{pH}$ and meat colour. In: Proceeding of $52^{\text {nd }}$ International Congress of Meat Science and Technology, Dublin, Ireland. pp. 181-182.

Rosenvolt, K. \& Andersen, H.J., 2005. Factors of significance for pork quality- a review. Meat Sci. 64, 219-237.

SAS, 2008. Statistical Analysis System User’s guide ( $2^{\text {nd }}$ Ed) (Version 9.2). SAS Institute Inc., Cary, North Carolina, USA.

Savel, J.W., Mueller, S.L. \& Baird, B.E., 2005. The chilling of carcasses- a review. Meat Sci. 70, 449-459.

Scheepers, M., 1999. Effect of breed on the quality of beef. MSc. Home Economics, University of Pretoria, South Africa.

Strydom, P.E., 1998. The characterization of indigenous cattle in relation to production and product characteristics. DSc. thesis, University of Free state, South Africa.

Swatland, H.P., 1984. Structure and Development of Meat Animals. Prentice Hall, Inc., Engelwood Cliffs, Ney Jersey 07632.

Vergara, H. \& Gallego, L., 2000. Effect of electrical stunning on meat quality of lamb. Meat Sci. 55, 345-349. 